\title{
Effect of Prenatal Teaching on Pregnancy Wellbeing
}

\author{
Megha Kadam ${ }^{1}$, Dr. S. G. Joshi ${ }^{2}$ \\ ${ }^{1}$ M. Sc. Nursing student, Symbiosis College of Nursing, Pune, Maharashtra, India \\ ${ }^{2}$ Professor, Head of the Department of Research and Statistics, Symbiosis College of Nursing, Pune, Maharashtra, India
}

\begin{abstract}
Pregnancy is a normal physiological process but a woman in India predisposes many complications during these days. Almost all of these complications occurred because of lack of knowledge regarding prenatal care and health facility in low-resource settings, and most could have been prevented. An interventional study was conducted to assessed the knowledge regarding prenatal care, to screen out high risk pregnancy and effectiveness of prenatal teaching. 60 women were selected by convenient sampling technique from antenatal OPD at selected hospitals in Pune city. Majority of the women 22 (36.6\%) were in age group of $>30 y e a r s .20$ (33.3\%) under 25 - 29 years of age and18 (30\%) under 19 - 24years. 42(70\%) women were primigravidas. 57 (95\%) had received two doses of tetanus toxoid immunization. $10 \%$ of them were under weight. $6.7 \%$ of them had oedema of legs and face. $6.7 \%$ of them had hypertension. Findings revealed that pretest knowledge score was less. After prenatal teaching 42(70\%) of them possess good knowledge and $18(30 \%)$ under average score. It was observed that there is significant difference between pretest and post test knowledge score. The findings suggest that increases in knowledge level after prenatal teaching and it helps to create awareness in community.
\end{abstract}

Keywords: Prenatal care, maternal mortality, pregnancy parameters, prenatal teaching, ante-natal OPD.

\section{Introduction}

The proposed study is mainly related to the "Maternal health". Its main focus is to highlight the Prenatal Care during pregnancy. In order to get a maximum level of general health one needs to improve the maternal and child health. Since twentieth century, due to increased maternal health services, maternal death in the India had been on a decline for all races. Still, huge racial inequalities in mortality rates existed. The prenatal period is moment of preparation of the women for child birth and maternity ${ }^{[1]}$, routine physical examinations are highly important to prevent serious complication that may occur during pregnancy ${ }^{[2]}$.

According to World Health Organization, 2015, it is estimated that, the globally everyday approximately 830 women died from preventable causes related to pregnancy and childbirth. At the end of 2015, roughly 3, 03,000 women died during and following pregnancy and childbirth. Almost all of these deaths occurred because of lack of knowledge regarding pregnancy and health facility in low-resource settings, and most could have been prevented ${ }^{[4]}$. An important external risk factor for pregnant women and newborn health is unbalanced nutrition of pregnant women [5],[ 6],[ 7]\&[ 8]. There was a statistically significant reduction in the proportion of women obtaining antenatal care services with increasing age, parity and number of children.

\section{Literature Survey}

Maternal mortality rates and Infant mortality rates are on rise at global as well as in India. The loss of life only because of lack of knowledge about care during pregnancy period, improper health facility and transportations mostly in tribal and hilly area. Since independence, there was a need to adopt maternal and child health services to reduce the losses.

Improving maternal health was one of the 8 Millennium Development Goals (MDGs) adopted by the international community in 2000. Under these, countries committed to reducing maternal mortality by 3 quarters between 1990 and 2015. Since 1990, the number of maternal deaths worldwide has dropped by $43 \%$. In sub-Saharan Africa, a number of countries halved their levels of maternal mortality. The high number of maternal deaths in some areas of the world reflects inequities in access to health services, and highlights the gap between rich and poor. Almost all maternal deaths (99\%) occur in developing countries. One target under Sustainable Development Goal 3 is to reduce the global maternal mortality ratio to less than 70 per $1,00,000$ births, with no country having a maternal mortality rate of more than twice the global average. As per India's maternal mortality rate is far away from this targets ${ }^{[9],[10] \&[11]}$.

According WHO, 2014, a woman loses her life every minute due to pregnancy related complication ${ }^{[12]}$. Most of these complications develop during pregnancy and most are preventable or treatable.The major causes of maternal mortality in India are anemia (19), antenatal and post natal hemorrhage (29.6), puerperal sepsis $(16 \%)$, obstructed labour $(9.5 \%)$, abortion $(8.9-12 \%)$, toxemia, sepsis $(8.3 \%)$ and other. Most of these causes can be prevented and controlled by taking appropriate care during pregnancy.

\section{Objectives}

(1) To assess health status of pregnant women and to screen out the high risk pregnancy. (2) To assess the knowledge regarding prenatal care. (3) To find out the effectiveness of prenatal teaching on selected parameter of pregnancy. (4) To correlate the finding with demographic variable.

\section{Problem Statement}

A study to assess effect of prenatal teaching on selected parameters related to pregnancy wellbeing among antenatal cases attending ANC OPD at selected hospitals in Pune city. 


\section{International Journal of Science and Research (IJSR) \\ ISSN (Online): 2319-7064}

Index Copernicus Value (2013): 6.14 | Impact Factor (2015): 6.391

\section{Problem Definitions}

1) Assess: According to Oxford dictionary to evaluate as estimate the nature value or quality.

In this study, it refers to knowledge gain in pregnant women regarding prenatal care.

2) Prenatal teaching: Prenatal education, is defined as a series of classes regarding care during pregnancy, i.e. provided health information to groups of pregnant women with goal of improve pregnancy and birth outcomes.

In this study, prenatal teaching is refers to systematic preplanned classes on selected parameters to pregnant women during pregnancy period.

3) Parameters

According to oxford dictionaries, parameters means measurable factor forming one set that defines a system or sets the condition of its operation.

In this study, parameters means parameters related to pregnancy such as diet, rest \& sleep, exercise, immunization, registration, preparation for delivery and child care.

4) Prenatal care

According to Text book of obstetrics, systematic supervision (examination and advice) of women during pregnancy is called prenatal care.

In this study, it refers to the prenatal period is moment of preparation of the women for child birth and maternity, routine physical examinations are highly important to prevent serious complication that may occur during pregnancy

\section{Material and Methods}

An interventional study was conducted during Feb-March 2016 in antenatal clinic of Ratna Memorial Hospital and Life Spring Maternity Home in Pune city. The quasi experimental research design was adopted to assess the effectiveness of prenatal teaching. 60 women were selected by convenient sampling technique from ante-natal OPD. A pre-tested semi structured questionnaire was used to obtain information on their socio-demographic variables as well as their knowledge regarding prenatal care concerning pregnancy. Data were collected in two parts. Pretest conducted on selected 60 samples and after that prenatal education given to participant for 20 to $40 \mathrm{~min}$. After prenatal teaching post test was conducted on seventh day. Data thus collected were analyzed by t-test method. A value less than 0.05 were considered statistically significant.

\section{Results}

Socio Demographic Characteristics Profile

\begin{tabular}{|l|l|l|}
\hline Demographic variable & Freq & $\%$ \\
\hline Age & & \\
\hline $19-24$ years & 18 & $30.0 \%$ \\
\hline $25-29$ years & 20 & $33.3 \%$ \\
\hline$>30$ years & 22 & $36.7 \%$ \\
\hline Gestational age (month) & & \\
\hline 6 month & 22 & $36.7 \%$ \\
\hline 7 month & 19 & $31.7 \%$ \\
\hline 8 month & 14 & $23.3 \%$ \\
\hline 9 month & 5 & $8.3 \%$ \\
\hline Religion & & \\
\hline
\end{tabular}

\begin{tabular}{|l|l|l|}
\hline Hindu & 43 & $71.7 \%$ \\
\hline Muslim & 5 & $8.3 \%$ \\
\hline Christian & 12 & $20.0 \%$ \\
\hline Educational status & & \\
\hline S.S.C. & 18 & $30.0 \%$ \\
\hline H.S.C. & 20 & $33.3 \%$ \\
\hline Graduate & 15 & $25.0 \%$ \\
\hline Post graduate & 7 & $11.7 \%$ \\
\hline Occupation & & \\
\hline Housewife & 40 & $66.7 \%$ \\
\hline Service & 17 & $28.3 \%$ \\
\hline Business & 3 & $5.0 \%$ \\
\hline Monthly income (Rs) & & \\
\hline$<5000 /-$ & 2 & $3.3 \%$ \\
\hline $5001-10000 /-$ & 30 & $50.0 \%$ \\
\hline $10001-15000 /-$ & 17 & $28.3 \%$ \\
\hline $15001-20000 /-$ & 11 & $18.3 \%$ \\
\hline
\end{tabular}

\begin{tabular}{|l|l|l|}
\hline Demographic variable & Freq & $\%$ \\
\hline Type of family & & \\
\hline Nuclear family & 31 & $51.7 \%$ \\
\hline Joint family & 29 & $48.3 \%$ \\
\hline Diet & & \\
\hline Vegetarian & 6 & $10.0 \%$ \\
\hline Non-vegetarian diet & 1 & $1.7 \%$ \\
\hline Mixed diet & 53 & $88.3 \%$ \\
\hline
\end{tabular}

\section{Description of samples based on their history taking and} examination

$70 \%$ of women were primigravida and $30 \%$ of had multigravida.Out of 60 women, few of them $6(10 \%)$ of them were under weight and $7(11.6 \%)$ of them were obeys. $6.7 \%$ of them had oedema of legs and face. $6.7 \%$ of them had hypertension and $1.7 \%$ was hypotensive. $18(30 \%)$ of women were anemic, $8.3 \%$ of them had urine albumin and $1.7 \%$ had presence of sugar in urine. $1.7 \%$ of them had past history of eclampsia and one percent was asthmatic. $88.3 \%$ of them had regular menstrual cycle. $1.7 \%$ of women had a present complained of gestational diabetes and $2(3.35 \%)$ women were had twins pregnancy. 5 (8.3\%) were had habit of alcohol, $9(15 \%)$ were had habit of smoking and tobacco and $4(6.6 \%)$ were allergic to drug and food.

\section{Knowledge of prenatal care -}

Table 1: Knowledge on parameters of pregnancy amongst ANC attenders

\begin{tabular}{|c|c|c|c|c|}
\hline $\begin{array}{c}\text { Parameters of prenatal } \\
\text { care }\end{array}$ & \multicolumn{2}{|c|}{ Pretest } & \multicolumn{2}{c|}{ Post test } \\
\cline { 2 - 5 } & Mean & SD & Mean & SD \\
\hline Prenatal care & 1.99 & 14.9 & 3.6 & 27.4 \\
\hline Prenatal Nutrition & 3.56 & 27.1 & 5.8 & 44.8 \\
\hline Exercise \& sleep & 1.65 & 12.5 & 2.2 & 16.8 \\
\hline $\begin{array}{c}\text { Prenatal registration, } \\
\text { visit \& immunization }\end{array}$ & 2.13 & 16.1 & 3.7 & 28.4 \\
\hline Preparation for delivery & 1.31 & 10.0 & 2.2 & 17.0 \\
\hline
\end{tabular}

Pretest constituted, $70 \%$ of women had average knowledge (score 9-16) and 30\% were under poor knowledge (score 08) regarding prenatal care. After prenatal teaching, in posttest $30 \%$ of pregnant women had average knowledge (score 9-16) and 70\% of them had good knowledge (score 17-24) regarding prenatal care. This indicates that there was remarkable improvement in the knowledge of pregnant women after prenatal teaching. It was found that, there was 


\section{International Journal of Science and Research (IJSR) \\ ISSN (Online): 2319-7064}

Index Copernicus Value (2013): 6.14 | Impact Factor (2015): 6.391

no significant association between the prenatal teaching and pregnancy wellbeing ( $\mathrm{t}$ values are greater than 0.05 ).

\section{Discussion}

In the study, it was found that majority of the women $36.6 \%$ were in age group of $>30$ years and $70 \%$ of them were primigravida, though most of them were elderly primi, $30 \%$ of them multigravida, who had previous deliveries at hospital. Early hospital registration and deliveries are a positive steps towards reduces maternal mortality ${ }^{[13]}$.

Out of 60 women, $10 \%$ of them were under weight, $30 \%$ of them were anemic, $8.3 \%$ were had habit of alcohol, $15 \%$ were had habit of smoking and tobacco. These leads to intrauterine growth retardation, low birth weight and preterm labour. A study conducted by SumithraMuthayya in 2009, shows that the prevalence of low birth weight (LBW) is higher in Asia than elsewhere, predominantly because of under nutrition of the mother prior to and during pregnancy. Which stated that $6.7 \%$ prematurely, $70 \%$ of mothers who delivered IUGR babies ${ }^{[14],[15]} .7 \%$ of them had hypertension and $1.7 \%$ was hypotensive. $8.3 \%$ of them had urine albumin and $1.7 \%$ had presence of sugar in urine. $1.7 \%$ of them had past history of eclampsia and one percent was asthmatic. $1.7 \%$ of women had a present complained of gestational diabetes and $2(3.35 \%)$ women were had twins pregnancy. The above value stated that these women had high risk pregnancy.

Prenatal care is very important aspect in reproductive and child health program. All prenatal health services are provided under a one roof called Ante-natal clinic. In the present study, it was found that $30 \%$ of them had poor knowledge. A study conducted by Mrs. RanjanaChavan in Pune also found that $31 \%$ of women had average knowledge regarding antenatal care ${ }^{[16]}$. Comparable to study by $\mathrm{U}$ Syed 10 in south Asia on knowledge and health seeking practices which shows that people having less knowledge regarding antenatal care and post natal care, which contributed to increase maternal mortality rate. This study reveals that widespread awareness on prenatal care is needed.

\section{Conclusion}

The present study revealed that many parameters regarding pregnancy and the knowledge about these parameters were found to be less. It was also observed that health education (prenatal teaching) increase knowledge score in respondents. Hospital registration and deliveries, immunization, nutrition, exercise and pre-preparation of delivery constituted to reduces the maternal mortality and morbidity. It was also observed that prenatal education system which imparting education to women was not observed in this set up because women attended the ante-natal clinic in her second visit $^{13}$ also their knowledge regarding ante-natal care was found very poor. According to $\mathrm{WHO}$, more than $80 \%$ of maternal deaths can be avoided by simple measures like early registration, health education, early detection of complication and off course prenatal education ${ }^{14}$.

\section{Recommendation}

1) Prenatal education classes for imparting education by using effective simple methods of teaching to women must be included in a private as well as in government sector.

2) These classes must be provided education in three steps preconception, prenatal care and post natal care.

\section{Acknowledgements}

The authors wish to sincerely thank the participants who took time to participate in this study.

\section{References}

[1] D. C. Dutta, "Text book of obstetrics", Sixth edition, New central book agency publication, p. $95-96$.

[2] World Health Organization, Annual Report on Maternal Mortality in 2015. Geneva: World Health Organization; 2015

[3] WHO, UNICEF, UNFPA. Maternal Mortality in 2010: Estimates Developed by WHO, UNICEF, UNFPA. Geneva: WHO, 2012.

[4] K. Park, "Text book of preventive and social medicine", 18th edition : Page No. 386.

[5] Darwall Smith G.F., Oxon B.Ch., Eng F.R.S.C. - An investigation into some of the effects of the state of nutrition of the mother during pregnancy and labour on the condition of the child at birth and for first few days of life. Nutrition,9 (4):388-92, 1993.

[6] Hasin A., Begum R., Khan M.R., Ahmed F. Relationship between birth weight and biochemical measures of maternal nutritional status at delivery in a Bangladeshi urban poor. Int. J. Food Sci.\&Nutr., 47(3):273-9, 1996.

[7] Mathews F., Yudkin P., Neil A. - Influence of maternal nutrition on outcome of pregnancy: prospective cohort study. [cited 10 April 2016]BMJ,319: 339-43, 1999.

[8] Rondo P.H., Abbott R., Rodriques L.C., Tomkins A.M. - The influence of maternal nutritional factors on intrauterine growth retardation in Brazil. Pediat. \&Perinat. Epidemiol., 11(2):152-66, 1997.

[9] [Internet]. 2016 [cited 17 May 2016]. Available from: http:// www.who.int/mediacentre/factsheet

[10] http://www.downtoearth.org.in/news/maternalmortality-india-likely-to-miss-mdg-target--49036

[11] Achievements Under Millennium Development Goals [Internet]. Pib.nic.in. 2016 [cited 17 May 2016]. Available from http://pib.nic.in/newsite/PrintRelease.aspx?relid=1236 69

[12] Health and population perspectives and issues 2005, 28(3) page No 154-163 NIHFW.

[13] International Journal of Research (IJR) e-ISSN: 23486848, p- ISSN: 2348-795X Volume 2, Issue 3, March 2015. [cited 22 April 2016]Available at http://internationaljournalofresearch.org. page 518-521

[14] Asian Academic Research Journal of Multidisciplinary(AARJMD) e- ISSN: 23192801XVolume3, ISSUE 4, April 2016. [cited 22 April 


\section{International Journal of Science and Research (IJSR) \\ ISSN (Online): 2319-7064}

Index Copernicus Value (2013): 6.14 | Impact Factor (2015): 6.391

2016]

Available

at

http://www.asianacademicresearch.org

[15] Indian Journal of Medical Research, 130, November 2009, page: 600-608. [cited 20 April 2016]Available at http://icmr.nic.in/ijmr/2009/november/1120.pdf

[16] International Journal of Nephrology, Volume 2012 (2012), Article ID 136942, 13 [cited 18 April 2016] http://dx.doi.org/10.1155/2012/136942

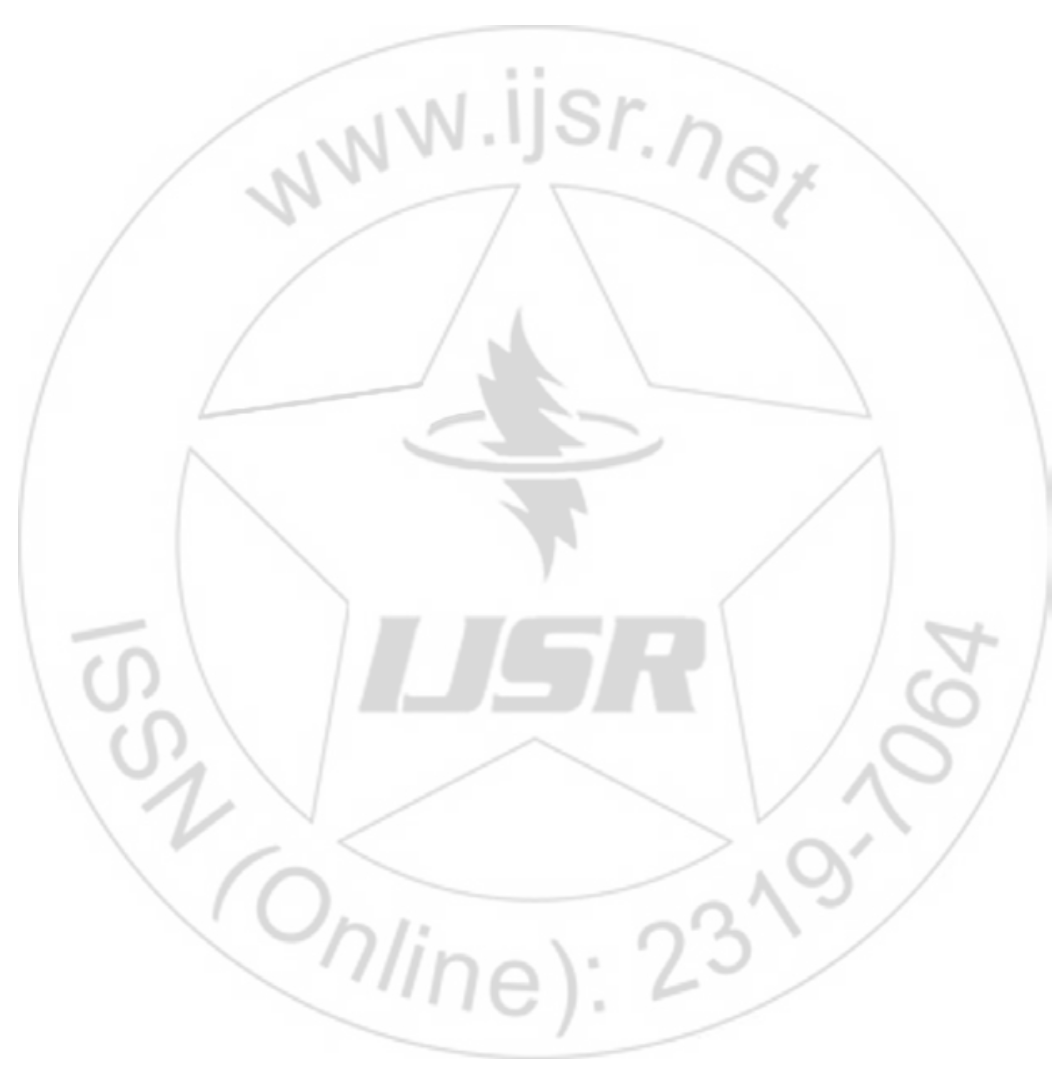

Volume 5 Issue 5, May 2016 www.ijsr.net 